\title{
Electrophysiological Analysis of Effect of Propranolol in Rabbit S2 Proximal Straight Tubule
}

\author{
Yoshiaki Kondo, Yutaka Igarashi, KeI Kudo*, \\ Nobuyuki Takahashi*, Osamu Ito*, Chiyoko N. Inoue, \\ Ikuma Fujiwara and Keishi Abe† \\ Department of Pediatrics, *Department of Clinical Biology \\ and Hormonal Regulation, and $\dagger$ the Socond Department of \\ Internal Medicine, Tohoku University School of Medicine, \\ Sendai 980
}

Kondo, Y., Igarashi, Y., Kudo, K., Takahashi, N., Ito, O., Inoue, C.N., Fujiwara, I. and AвE, K. Electrophysiological Analysis of Effect of Propranolol in Rabbit S2 Proximal Straight Tubule. Tohoku J. Exp. Med., 1994, 172 (1), 2938 - The effect of dl-propranolol on the basolateral membrane potential ( $\mathrm{Vb}$ ) of in vitro microperfused $\mathrm{S} 2$ proximal straight tubules of the rabbit kidney was examined using conventional microelectrode techniques. In the steady-state condition, the average of 23 measurements of $\mathrm{Vb}$ was $-44.8 \pm 2.0 \mathrm{mV}$. Addition of $10^{-4} \mathrm{~mol} / \mathrm{l}$ of dl-propranolol to the basolateral solution rapidly depolarized $\mathrm{Vb}$ by $12.1 \pm 1.3 \mathrm{mV}$ in $20 \mathrm{sec}(n=15)$. The same dose of d-isomer of propranolol, which has no beta-blocking effect, also depolarized $\mathrm{Vb}$ to a similar extent. The non-selective beta-blocker nadolol, which possesses no membrane stabilising activity, had no effect on $\mathrm{Vb}$. Depolarization of $\mathrm{Vb}$ by dl-propranolol in 20 seconds (propranolol-induced $\Delta \mathrm{Vb}$ ) occurred in a dose-dependent manner. In the presence of $1 \mathrm{mmol} / 1 \mathrm{Ba}^{++}$in basolateral solution, propranolol-induced $\Delta \mathrm{Vb}$ was strongly inhibited. The stilbene derivative DIDS at $1 \mathrm{mmol} / 1$ did not change propranolol-induced $\Delta \mathrm{Vb}$, whereas the elimination of $\mathrm{C1}^{-}$from the ambient conditions increased propranolol-induced $\Delta \mathrm{Vb}$. The minimization of the luminal $\mathrm{Na}^{+}$-coupled organic solute transporter by collapsing of the lumen did not inhibit propranolol-induced $\Delta \mathrm{Vb}$, indicating the lack of effect of propranolol on luminal $\mathrm{Na}^{+}$-coupled transporters. Ouabain at $10^{-3} \mathrm{mmol} / \mathrm{l}$ in the bath did not eliminate propranolol-induced $\Delta \mathrm{Vb}$, indicating the presence of a target transporter other than $\mathrm{Na}^{+} / \mathrm{K}^{+}$ATPase for propranolol. These results suggest the following; 1) propranolol has a depolarizing effect on $\mathrm{Vb}$ in proximal tubule; 2) the effect of propranolol is independent of $\mathrm{Cl}^{-}$transport or $\mathrm{Na}^{+}$-coupled transporters in the luminal membrane; 3) propranolol depolarizes $\mathrm{Vb}$ by inhibiting the $\mathrm{K}^{+}$channel in the basolateral membrane of S2 proximal tubule. - microelectrode; potassium channel; in vitro microperfusion; $\beta$-adrenergic receptor; barium

Received May 11, 1993; revision accepted for publication December 15, 1993.

Address for reprints: Yoshiaki Kondo, M.D., Department of Pediatrics, Tohoku University School of Medicine, 1-1 Seiryo-machi, Aoba-ku, Sendai 980, Japan. 
The effect of propranolol as a $\beta$-adrenergic blocker has been characterized well due to its important pharmacological uses in cardiac and hypertensive diseases (Dollery 1988; Nadelmann and Frishman 1990). Because of its specific antagonistic effect on $\beta$-receptors in the kidney, it has also proved useful in investigations of the physiological role of $\beta$-adrenergic agonists. In addition to its beta-antagonistic action, propranolol has a nonspecific membrane stabilising effect (MSE), also called a local anesthetic effect. These terms are derived from the non-specific effects of various compounds which inhibit the inotropic and chronotropic functions of cardiac muscles. The exact nature of the MSE is still unclear because of the difficulty of identifying the transport systems involved in this effect. In the kidney, the MSE of propranolol was first described by Nakamura and Imai (1982), who demonstrated the specific binding of ${ }^{3} \mathrm{H}$ propranolol mainly to the distal nephron, including the distal convoluted, connecting and collecting tubules. Because the binding constant of propranolol to these segments was as low as the level of mmol/l, these authors postulated that the observed binding site of propranolol was the segment on which the drug exerted in MSE. They also roported that both dl- and d-propranolol at relatively higher concentrations suppressed lumen-negative transepithelial voltage of connecting and cortical collecting tubules, indicating the presence of nonspecific effect of propranolol on membrane transport of ions (Imai and Nakamura 1982).

Recently, we demonstrated presence of $\beta$-adrenergic receptors in the proximal straight tubule of the rabbit kidney (Kudo et al. 1991). In our study, we found that a high dose of propranolol depolarized the basolateral membrane potential $(\mathrm{Vb})$ of the $\mathrm{S} 2$ proximal straight tubule, whereas a low dose of propranolol had no effect on $\mathrm{Vb}$. In order to elucidate the mechanism of this depolarization, we conducted a series of studies using conventional intracellular microelectrode techniques in the in vitro microperfused rabbit proximal S2 straight tubule. Our data demonstrate a depolarizing effect of both $\mathrm{d}$ - and l-propranolol, indicating that the effect is independent of $\beta$-specific antagonistic activity. Nadolol, which belongs to the same class of non-selective $\beta$-antagonists, had no effect on $\mathrm{Vb}$.

\section{Methods And Materials}

\section{In vitro microperfusion of proximal tubules}

Japanese white rabbits weighing 1.5 to $2.0 \mathrm{~kg}$ were anesthetized with $50 \mathrm{mg} / \mathrm{kg}$ of pentobarbital given intravenously. The left kidney was removed and thin slices were made, and transferred to a chilled dish containing a dissection medium of the following composition in mmol/l: $80 \mathrm{KCl}, 14 \mathrm{KH}_{2} \mathrm{PO}_{4}, 44 \mathrm{~K}_{2} \mathrm{HPO}_{4}, 9 \mathrm{NaHCO}_{3}, 160$ sucrose. A fragment of $\mathrm{S} 2$ proximal straight tubule was microdissected with fine forceps from the middle portion of the cortical medullary ray under a stereoscopic microscope. The tubule segment was transferred to a perfusion chamber mounted on a stage of the inverted microscope (IMT-2, Olympus, Tokyo). By using Narishige's micromanipulator (Narishige, Tokyo), the dissected tubule was microperfused inside and out with control Ringer's solution by Burg's method with slight modifications (Burg et al. 1966). For exchange of solution in the bath, a custom-made 8-channel rotary valve was installed in the system. 


\section{Microelectrode study}

To prepare the microelectrodes, we purchased aluminosilicate glass tubes (Supremax, Schott, FRG) with an outer diameter of $8.0 \mathrm{~mm}$ and an inner diameter of $5.5 \mathrm{~mm}$. The glass tubes were first heated and stretched to form the inner filaments. The original glass tubes were modified to outer diameters of $1.5 \mathrm{~mm}$. The capillary was further pulled to form the final tip of the electrode by Narishige's PE-2 vertical puller (Narishige). The electrode was filled with $1 \mathrm{~mol} / \mathrm{l}$ of $\mathrm{KCl}$ and inserted into an $\mathrm{Ag} / \mathrm{AgCl}$ electrode holder of a WPI FD-223 electrometer (WP-Instrument, New Haven, CT, USA). The electrical potential was measured by a single channel of the FD-223 electrometer. Micromanipulation of the electrode was performed by a hydrolic micromanipulator MW-2 (Narishige). The microelectrode was inserted from the basolateral side and basolateral membrane voltage $(\mathrm{Vb})$ was monitored continuously. A reference electrode of $3 \mathrm{~mol} / \mathrm{l} \mathrm{KCl}$ flowing boundary was constructed as described previously (Kudo et al. 1991). The reference electrode was placed in the perfusion chamber on the stage of the inverted microscope near the tubule. The tip of the reference electrode was approximately $20 \mu \mathrm{m}$ and its resistance was several kiloohms.

\section{Chemicals}

4, 4'-diisothiocyanostilbene-2, 2'-disulfonic acid (DIDS), and dl-, d-, and l-propranolol were purchased from Sigma Chemical Company (St. Louis, MO, USA). All other chemicals were reagent grade and purchased from Wako Pure Chemicals (Osaka).

\section{Statistical analysis}

All the statistical analyses were performed with Student's paired or non-paired $t$-test, as necessary.

\section{RESULTS}

Effect of $l$-, and dl-propranolol on $\mathrm{Vb}$

In 23 proximal tubule cells, the average $\mathrm{Vb}$ was $-44.8 \pm 2.0 \mathrm{mV}$. To examine whether propranolol has a direct effect on $\mathrm{Vb}$, we applied $10^{-4} \mathrm{~mol} / \mathrm{l}$ of 1 - and dl-propranolol to the basolateral side of the tubule and observed changes in $\mathrm{Vb}$. As shown in Fig. 1, both 1- and dl-propranolol rapidly depolarized Vb by approximately $10 \mathrm{mV}$. The depolarization was reversed rapidly by removal of propranolol.

The dose-dependence of the effect of dl-propranolol on $\mathrm{Vb}$ was also examined, and is summarized in Fig. 2. The amplitude of depolarization, $\Delta \mathrm{Vb}$, was measured 20 seconds after propranolol was applied to the bath. Propranolol at $10^{-4} \mathrm{~mol} / \mathrm{l}$ depolarized $\mathrm{Vb}$ to a greater extent than at $10^{-5} \mathrm{~mol} / \mathrm{l}$. At $10^{-7} \mathrm{~mol} / \mathrm{l}$, we observed no effect of propranolol.

The effect of dl-, l-, and d-propranolol at $10^{-4} \mathrm{~mol} / \mathrm{l}$ on $\mathrm{Vb}$ is summarized in Fig. 3. Although 1-propranolol depolarized $\mathrm{Vb}$ to a greater extent than $\mathrm{d}-$ propranolol, both isomers exerted a depolarizing effect, and magnitude of these effects was similar.

\section{Effect of nadolol on $\mathrm{Vb}$}

To investigate whether the effect of propranolol is related to its non-selective $\beta$-antagonistic action, we also examined the effect of nadolol, a non-selective 


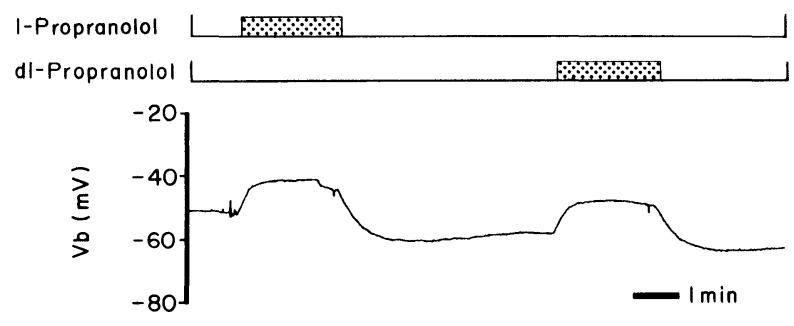

Fig. 1. A representative recording of the effect of l- and dl-propranolol on $\mathrm{Vb}$. Addition of $0.1 \mathrm{mmol} / 1$ of 1-propranolol, a $\beta$-adrenergic antagonist, caused reversible depolarization of $\mathrm{Vb}$ by approximately $12 \mathrm{mV}$ in 20 sec. Subsequent addition of dl-propranolol at the same concentration caused the same magnitude of depolarization, indicating that d-propranolol, the inactive isomer of the l-type, has the same effect on $\mathrm{Vb}$ as the l-type.

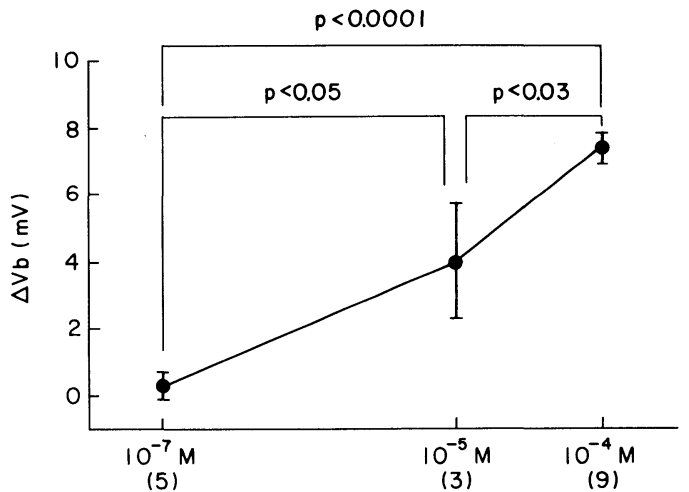

Fig. 2. Dose-dependence of the effect of dl-propranolol on $\mathrm{Vb}$. Whereas $10^{-7}$ $\mathrm{mol} / \mathrm{l}$ propranolol caused no visible depolarization of $\mathrm{Vb}, 10^{-5}$ and $10^{-4} \mathrm{~mol} / \mathrm{l}$ of propranolol caused substantial depolarizations of $\mathrm{Vb}$ in a dose-dependent manner.

$\beta$-antagonist, on $\mathrm{Vb}$. Fig. 4 clearly shows that nadolol only slightly shifted $\mathrm{Vb}$ to a hyperpolarized state without depolarizing $\mathrm{Vb}$, whereas dl-propranolol completely depolarized $\mathrm{Vb}$. The figure also demonstrates that the effect of propranolol was strongly inhibited by the addition of $\mathrm{Ba}^{++}$to the bath.

\section{Effect of lumen collapse on propranolol-induced depolarization of $\mathrm{Vb}$}

To further characterize the effect of propranolol, we investigated the mechanism of depolarization by propranolol. In the first protocol, we tested whether the inhibition of luminal transporters produced by stopping luminal perfusion and collapsing the lumen of the proximal tubule, led to the disappearance of the effect of propranolol. As shown in Fig. 5, propranolol-induced depolarization was not inhibited by collapsing of the lumen, indicating that propranolol-induced depolarization of $\mathrm{Vb}$ is not linked to the luminal ion transport systems such as 


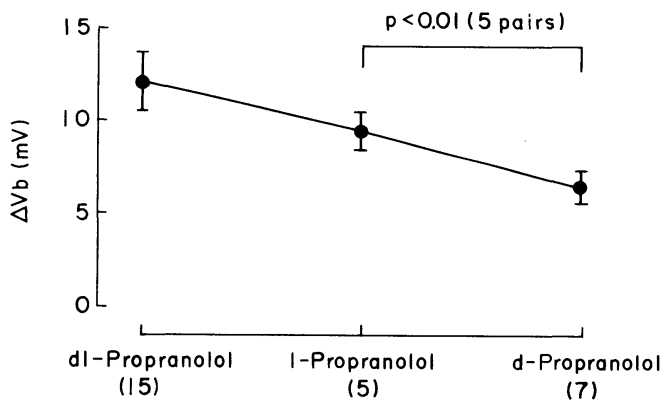

Fig. 3. Comparison of the effects of various isomers of propranolol on $\mathrm{Vb}$. The effects of dl-, l- and d-isomers of propranolol on $\mathrm{Vb}$ are summarized. Each data set was compared with other sets by Student's paired $t$-test. Although the difference in magnitude of depolarization between l- and d-propranolol was statistically significant, the results show that both l- and d-isomers of propranolol exert a depolarizing effect on $\mathrm{Vb}$. The observation indicates that the depolarizing effect of propranolol may be independent of its $\beta$-antagonistic action.

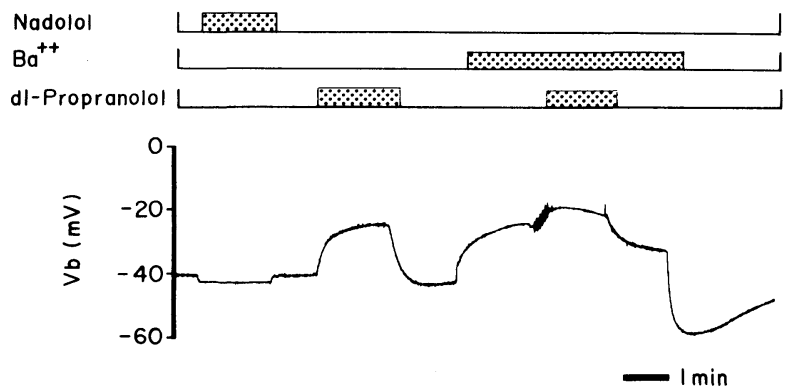

Fig. 4. Effects of nadolol and dl-propranolol on $\mathrm{Vb}$. A representative record is shown with $0.1 \mathrm{mmol} / 1$ of nadolol and of dl-propranolol. Addition of 0.1 $\mathrm{mmol} / \mathrm{l}$ of nadolol to the bath slightly hyperpolarized $\mathrm{Vb}$ without gradual depolarization, which was observed when $0.1 \mathrm{mmol} / \mathrm{l}$ of dl-propranolol was applied to the bath subsequently. Addition of $1 \mathrm{mmol} / \mathrm{l}$ of $\mathrm{Ba}^{++}$to the bath depolarized Vb by approximately $18 \mathrm{mV}$. Depolarization of Vb by propranolol was significantly less in the presence of $\mathrm{Ba}^{++}$.

$\mathrm{Na}^{+}$-glucose cotransporter and $\mathrm{Na}^{+} / \mathrm{H}^{+}$antiporter.

\section{Effect of $\mathrm{Cl}^{-}$removal on propranolol-induced depolarization of $\mathrm{Vb}$}

We also tested whether $\mathrm{Cl}^{-}$transport was involved in the propranololinduced depolarization, by eliminating the ambient $\mathrm{Cl}^{-}$while the tubular lumen was collapsed due to cessation of luminal perfusion. The results are summarized in Fig. 6. In the control period, $10^{-4} \mathrm{~mol} / \mathrm{l}$ of dl-propranolol depolarized $\mathrm{Vb}$ by $+7.1 \pm 1.7 \mathrm{mV}(n=4)$ in 20 seconds. In the absence of $\mathrm{Cl}^{-}$, propranolol depolarized $\mathrm{Vb}$ by $+11.8 \pm 3.2 \mathrm{mV}(n=4)$, which was not significantly different 


Lumen collapsed $\mathrm{L}$

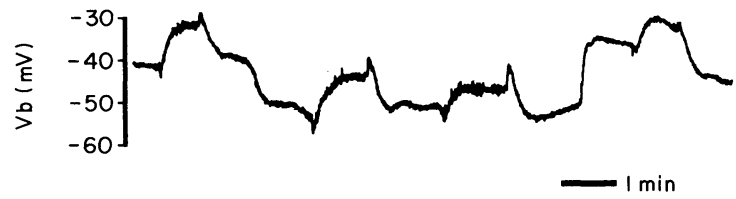

Fig. 5. Effect of collapsing of the tubule lumen on propranolol-induced depolarization of $\mathrm{Vb}$. Effect of $10^{-4} \mathrm{~mol} / \mathrm{l}$ of dl-propranolol on $\mathrm{Vb}$ was observed while the tubule was not perfused. As is clearly seen, collapsing the tubular lumen did not abolish the propranolol-induced depolarization of $\mathrm{Vb}$, whereas collapsing itself rapidly hyperpolarized $\mathrm{Vb}$, indicating that the transporters in the luminal membrane may not be responsible for propranolol-induced depolarization.

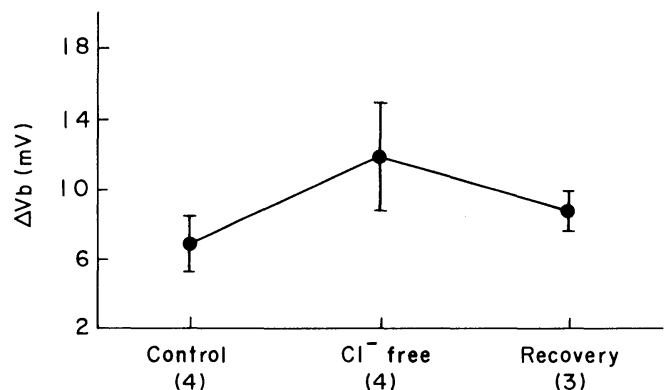

Fig. 6. Effect of ambient $\mathrm{Cl}^{-}$removal on propranolol-induced depolarization of $\mathrm{Vb}$. After the depolarization of $\mathrm{Vb}$ by $10^{-4} \mathrm{~mol} / \mathrm{l}$ of dl-propranolol, the lumen was collapsed and then ambient $\mathrm{Cl}^{-}$was substituted for gluconate. In each condition, the effect of propranolol on $\mathrm{Vb}$ was examined. The result shows that the elimination of $\mathrm{Cl}^{-}$from the ambient solution did not inhibit the depolarization induced by propranolol, indicating that propranololinduced depolarization of $\mathrm{Vb}$ was independent of $\mathrm{Cl}^{-}$transport.

from the control value. When $\mathrm{Cl}^{-}$was readded to the ambient solution, propranolol depolarized $\mathrm{Vb}$ to the same extent $(+8.7 \pm 0.8, n=3)$.

\section{Effect of transport inhibitors on propranolol-induced depolarization}

To test whether the $\mathrm{Na}^{+}-\mathrm{HCO}_{3}{ }^{-}$cotransporter or $\mathrm{Cl}^{-} / \mathrm{HCO}_{3}{ }^{-}$antiporter were involved in propranolol-induced depolarization, the effect of the stilbene derivative 4, $4^{\prime}$-diisothiocyanostilbene-2, $2^{\prime}$-disulfonic acid (DIDS) on the depolarization was also examined. DIDS at this concentration hyperpolarized Vb rapidly by $6.0 \pm 2.1 \mathrm{mV}$ in $30 \mathrm{sec}(n=6)$. A representative study depicted in Fig. 7 clearly shows that $0.5 \mathrm{mmol} / 1$ of DIDS did not inhibit propranolol-induced depolarization, whereas DIDS itself rapidly hyperpolarized $\mathrm{Vb}$. The effect of inhibition of $\mathrm{Na}^{+} / \mathrm{K}^{+}$ATPase by ouabain was also examined. Ouabain $1 \mathrm{mmol} / \mathrm{l}$ itself de- 


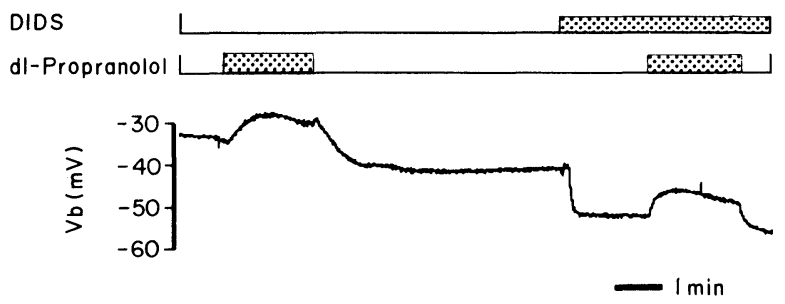

Fig. 7. Effect of DIDS on propranolol-induced depolarization. Addition of 0.5 $\mathrm{mmol} / 1$ of DIDS to the bath hyperpolarized $\mathrm{Vb}$ by approximately $12 \mathrm{mV}$. In the presence of DIDS in the bath, $0.1 \mathrm{mmol} / 1$ of dl-propranolol depolarized $\mathrm{Vb}$ by $8 \mathrm{mV}$, indicating that DIDS does not inhibit propranolol-induced depolarization.

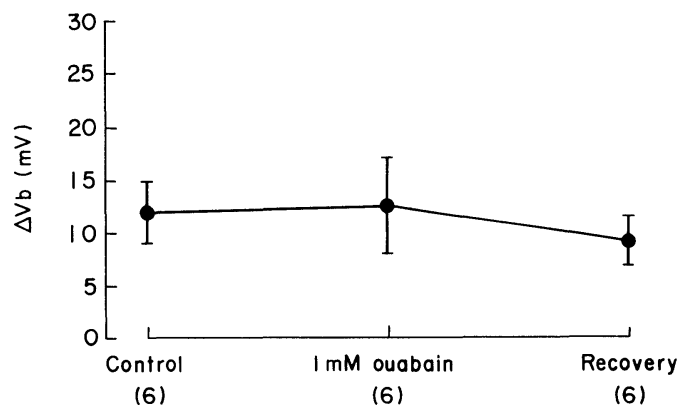

Fig. 8. Effect of ouabain on propranolol-induced depolarization. Effect of 1 $\mathrm{mmol} / \mathrm{l}$ of ouabain on depolarization of $\mathrm{Vb}$ induced by $0.1 \mathrm{mmol} / \mathrm{l}$ of $\mathrm{dl}-$ propranolol was examined. After propranolol-induced depolarization in the absence of ouabain was observed, $1 \mathrm{mmol} / \mathrm{l}$ of ouabain was applied to the bath. Propranolol-induced depolarization was observed 20 seconds later. After ouabain was rinsed from the bath, propranolol-induced depolarization was observed again. In the control period, $0.1 \mathrm{mmol} / 1$ of dl-propranolol depolarized $\mathrm{Vb}$ by $+12.0 \pm 1.2 \mathrm{mV}(n=6)$. In the presence of ouabain in the bath, propranolol depolarized $\mathrm{Vb}$ by $+12.5 \pm 1.8 \mathrm{mV}(n=6)$, indicating that ouabain does not affect propranolol-induced depolarization.

polarized $\mathrm{Vb}$ by $9.0 \pm 3.0 \mathrm{mV}$ in one minute $(n=6)$. As shown in Fig. 8 , the magnitude of depolarization one minute after addition of ouabain compared with the control value, indicated that propranolol-induced depolarization was not the result of inhibition of the $\mathrm{Na}^{+}$-pump.

\section{Effect of propranolol on $\mathrm{K}^{+}$conductance}

To investigate whether propranolol-induced depolarization was the result of the inhibition of $\mathrm{K}^{+}$conductance in the basolateral membrane of the proximal tubule, we depolarized $\mathrm{Vb}$ with one $\mathrm{mmol} / \mathrm{l}$ of $\mathrm{Ba}^{++}$, and examined the effect of dl-propranolol on $\mathrm{Vb}$. One mmol/l $\mathrm{Ba}^{++}$depolarized $\mathrm{Vb}$ by $+15.7 \pm 4.0 \mathrm{mV}$ in one minute $(n=6)$. As shown in Fig. 9, propranolol-induced depolarization was 


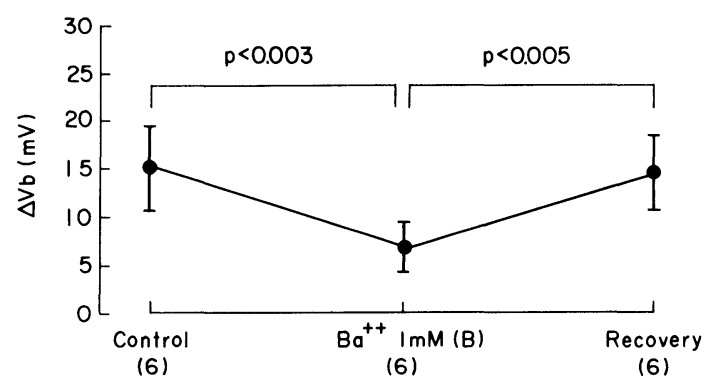

Fig. 9. Effect of barium on propranolol-induced depolarization. Propranololinduced depolarization in the presence and absence of $1 \mathrm{mmol} / 1$ of $\mathrm{Ba}^{++}$was observed. In the control period, $0.1 \mathrm{mmol} / \mathrm{l}$ of dl-propranolol depolarized $\mathrm{Vb}$ by $+15.0 \pm 1.8 \mathrm{mV}$ in 6 cells. Propranolol-induced depolarization 1 minute after application of $\mathrm{Ba}^{++}$to the bath in the same cells was $6.9 \pm 0.9 \mathrm{mV}$, which was significantly less than that in the control period $(p<0.003)$. The removal of $\mathrm{Ba}^{++}$from the bath restored the propranolol-induced depolarization. These results indicate that propranolol-induced depolarization is inhibited by $\mathrm{Ba}^{++}$in the bath.

significantly decreased in the presence of $\mathrm{Ba}^{++}$. These results indicate that propranolol may inhibit $\mathrm{K}^{+}$conductance.

\section{Discussion}

It is well established that the mortality rate associated with the hypertensive state can be diminished by using this specific antagonist. Nevertheless, it is also known that its characteristic adverse effect, the membrane stabilising activity (MSE), causes the deterioration of the cardiac function by inhibiting cardiac contractility, thereby increasing the mortality rate. Although propranolol lacks intrinsic sympathomimetic action, it does exert MSE. This pharmacological property, although generally regarded as insignificant in therapeutic use, may be responsible for death in more than $30 \%$ of fatal overdose cases (Henry and Cassidy 1986). This problem led to the development of many other $\beta$-adrenergic antagonists such as nadolol and timolol. Nevertheless, propranolol is still an important antihypertensive drug because of its clinical availability.

In the present paper, we demonstrated a non-specific effect of propranolol on the renal tubular function, which is not related to its $\beta$-antagonistic activity. Although we do not know whether the effect of propranolol we observed is the same phenomenon as MSE, its effect on renal tubule already occurs at the maximal pharmacological dose of propranolol in clinical use.

The most important finding is that propranolol causes moderate depolarization, which is similar to that we observed with $\beta$-agonist isoproterenol (Kudo et al. 1991). There are many possible causes of depolarization of $\mathrm{Vb}$ in the proximal tubule, including several transporters, which may change $\mathrm{Vb}$. The first is the rheogenic $\mathrm{Na}^{+}-\mathrm{HCO}_{3}{ }^{-}$cotransporter in the basolateral membrane. This transpor- 
ter carries at least two negative charges and its activation may cause the depolarization of $\mathrm{Vb}$, as occurs when the basolateral $\mathrm{HCO}_{3}{ }^{-}$is lowered (Yoshitomi et al. 1985). Our data, however, indicate that this cotransporter may not be involved because DIDS, the powerful inhibitor of this transporter, in the basolateral side did not eliminate the depolarizing effect of propranolol.

Second, the $\mathrm{Na}^{+}$-coupled solute transporters such as the $\mathrm{Na}^{+}$-glucose transporter and $\mathrm{Na}^{+}$-alanine cotransporter in the luminal membrane (Ullrich et al. 1974; Samarzija and Frömter 1982), when stimulated, may carry more positive charges into the cell, thereby depolarizing $\mathrm{Vb}$. Nevertheless, in our study, inhibition of such transporters by collapsing of the tubule did not dissipate the propranololinduced depolarization.

The third relevant transporter is $\mathrm{Na}^{+} / \mathrm{K}^{+}$ATPase. This transporter in the proximal tubule is known to carry a positive charge by its coupling ratio of $3 \mathrm{Na}^{+}$ and $2 \mathrm{~K}^{+}$exchanged across the basolateral membrane. Our data show that the strong inhibition of $\mathrm{Na}^{+} / \mathrm{K}^{+}$ATPase by a high dose of ouabain did not inhibit propranolol-induced depolarization. This observation suggested that the inhibition of $\mathrm{Na}^{+} / \mathrm{K}^{+}$ATPase alone cannot explain the entire mechanism of the dopolarization and that propranolol modulates other transporters.

The fourth and the most plausible candidate for the transporter which is modulated by propranolol is $\mathrm{K}^{+}$conductance in the basolateral membrane. The inhibition of this conductance may also depolarize $\mathrm{Vb}$. $\mathrm{Ba}^{++}$, the potent $\mathrm{K}^{+}$ channel blocker, inhibited propranolol-induced depolarization, suggesting that the modulation of $\mathrm{K}^{+}$conductance in the basolateral membrane is involved in propranolol-induced depolarization.

Thus far, various types of $\mathrm{K}^{+}$channels have been identified in both luminal and basolateral membrane of the proximal tubule. As for the basolateral membrane of the proximal tubule cells, $\mathrm{K}^{+}$channels were found in the basolateral membrane of the proximal convoluted tubule (Gogelein and Greger 1987; Sackin and Palmer 1987; Parent et al. 1988; Hunter 1990; Jacobsen et al. 1990; Kawahara 1990; Sackin 1990; Hunter 1991). A stretch-activated $\mathrm{K}^{+}$channel sensitive to cell volume was found in the basolateral membrane of Necturus proximal tubule (Sackin 1989) and of Xenopus kidney proximal tubule cells (Kawahara 1990). Our data do not discriminate which channel is involved in propranololinduced depolarization. Further studies are necessary to elucidate this point.

\section{Acknowledgment}

We thank Prof. Imai and Prof. Nishiyama for their excellent criticism. We are grateful to Miss Nozaki and Miss Mezawa for technical assistance. The present work was supported in part by a grant-in-aid for scientific research from the Ministry of Education, Science, and Culture of Japan. 


\section{References}

1) Burg, M., Grantham, J., Abramow, M. \& Orloff, J. (1966) Preparation and study of fragments of single rabbit nephron. Am. J. Physiol., 210, 1293-1298.

2) Dollery, C.T. (1988) Beta-adrenoceptor blockade: Past, present, and future. $J$. Cardiovasc. Pharmacol., 11, Suppl 2S, 1-4.

3) Gogelein, H. \& Greger, R. (1987) Properties of single $\mathrm{K}^{+}$channels in the basolateral membrane of rabbit proximal straight tubules. Pflügers Arch., 410, 288-295.

4) Henry, J.A. \& Cassidy, S.L. (1986) Membrane stabilising activity: A major cause of fatal poisoning. Lancet., 1, 1414-1417.

5) Hunter, M. (1990) Stretch-activated channels in the basolateral membrane of single proximal cells of frog kidney. Pflügers Arch., 416, 448-453.

6) Hunter, M. (1991) Potassium-selective channels in the basolateral membrane of single proximal tubule cells of frog kidney. Pflügers Arch., 418, 26-34.

7) Imai, M. \& Nakamura, R. (1982) Function of distal convoluted and connecting tubules studied by isolated nephron fragments. Kidney Int., 22, 465-472.

8) Jacobsen, C., Blokkebak, P.J. \& Sheikh, M.I. (1990) Potassium channels in basolateral membrane vesicles from pars convoluta of rabbit proximal tubule. FEBS Lett., 269, 315-8.

9) Kawahara, K. (1990) A stretch-activated $\mathrm{K}^{+}$channel in the basolateral membrane of Xenopus kidney proximal tubule cells. Pfü̈gers Arch., 415, 624-629.

10) Kudo, K., Kondo, Y., Abe, K., Igarashi, Y., Tada, K. \& Yoshinaga, K. (1991) Evidence for presence of functional beta-adrenoceptor in rabbit S2 proximal straight tubules. Am. J. Physiol., 261, F393-F399.

11) Nadelmann, J. \& Frishman, W.H. (1990) Clinical use of beta-adrenoceptor blockade in systemic hypertension. Drugs, 39, 862-876.

12) Nakamura, R. \& Imai, M. (1982) Nephron distribution of ${ }^{3} \mathrm{H}$-dihydroalprenolol binding and its physiological significance. Jpn. J. Nephrol., 5, 70.

13) Parent, L., Cardinal, J. \& Sauve, R. (1988) Single-channel analysis of a K channel at basolateral membrane of rabbit proximal convoluted tubule. Am. J. Physiol., 254, F105-F113.

14) Sackin, H. (1989) A stretch-activated $\mathrm{K}^{+}$channel sensitive to cell volume. Proc. Natl. Acad. Sci. USA, 86, 1731-1735.

15) Sackin, H. (1990) Regulation of renal proximal tubule basolateral potassium channels. Prog. Clin. Biol. Res., 334, 231-249.

16) Sackin, H. \& Palmer, L.G. (1987) Basolateral potassium channels in renal proximal tubule. Am. J. Physiol., 253, F476-F487.

17) Samarzija, I. \& Frömter, E. (1982) Electrophysiological analysis of rat renal sugar and amino acid transport. III. Neutral amino acids. Pfü̈gers Arch., 393, 199-209.

18) Ullrich, K.J., Rumrich, G. \& Kloss, S. (1974) Sodium dependence of the amino acid transport in the proximal convolution of the rat. Pflügers Arch., 351, 49.

19) Yoshitomi, K., Burckhardt, B.C. \& Frömter, E. (1985) Rheogenic sodium-bicarbonate cotransport in the peritubular cell membrane of rat renal proximal tubule. Pflügers Arch., 405, 360-366. 